\title{
Synthesis and characterisation of potassium polytitanate for photocatalytic degradation
} of crystal violet

Mohammad Shahid ${ }^{1}$, Ibrahim El Saliby ${ }^{1}$, Andrew McDonagh ${ }^{2}$, Leonard D. Tijing ${ }^{1}$, Jong-Ho $\mathrm{Kim}^{3,4}$, Ho Kyong Shon ${ }^{1, *}$

1. School of Civil and Environmental Engineering, University of Technology, Sydney (UTS), P.O. Box 123, Broadway, Sydney NSW 2007, Australia

2. School of Chemistry and Forensic Science, University of Technology, Sydney (UTS), P.O. Box 123, Broadway, Sydney NSW 2007, Australia

3. School of Applied Chemical Engineering \& The Research Institute for Catalysis, Chonnam National University, Gwangju 500-757, Korea

4. Photo \& Environmental Technology Co., Ltd, Gwangju 500-460, Korea

Received 25 December 2013

Revised 14 February 2014

Accepted 06 March 2014

\begin{abstract}
Potassium titanate nanostructures were synthesised by hydrothermal treatment of $\mathrm{TiO}_{2}(\mathrm{P} 25)$ in $\mathrm{KOH}$ and $\mathrm{H}_{2} \mathrm{O}_{2}$. As-produced powders were characterised by scanning electron microscopy, energy-dispersive X-ray spectroscopy, transmission electron microscopy, X-ray diffraction, and nitrogen adsorption-desorption methods. Longitudinally-oriented-wire-like structures with a length up to several micrometres and diameters ranging from 10 to $30 \mathrm{~nm}$ were obtained. Larger size fibrous nanowires resulting from the hydrothermal treatment showed high affinity in adsorbing crystal violet $(\mathrm{CV})$, which was mainly due to their high surface area. The photocatalytic bleaching of $\mathrm{CV}$ solution revealed that the wires are photoactive under UV light irradiation. Macroporous nanowires are considered as effective adsorbents of $\mathrm{CV}$, capable of its photocatalytic degradation, and they can be easily separated from the solution by settling.
\end{abstract}

\section{Key words}

Potassium titanate

Adsorption

Crystal violet 
Macroporous

Titanium dioxide

Photocatalysis

*Corresponding author. E-mail: hokyong.shon-1@uts.edu.au（Ho Kyong Shon）

\section{Introduction}

Nanostructured titanates produced by hydrothermal treatment of titanium dioxide $\left(\mathrm{TiO}_{2}\right)$ with strong alkaline solutions have generated much interest due to their unique combination of physico-chemical (Bavykin et al., 2006; Chen and Mao, 2007; Morgan et al., 2008) and structural (Chen and Peng, 2007; Yang et al., 2003) properties. Titanates, typically potassium titanate, exhibit attractive physico-chemical properties owing to their distinct crystal structures, which show great potential for cation exchange, catalysis (Izawa et al., 1982; Lee et al., 2000; Um et al., 2001) and photocatalysis (Dmitry et al., 2008; Ishihara et al., 2002; Zhuang et al., 2007).

Numerous potassium titanates, each with unique crystal structures containing layered and tunnel structures, have been synthesised (Berry et al., 1960; Masaki et al., 2000). Potassium titanates can be fabricated in the form of whiskers and fibres and have found applications as photocatalysts for water cleavage (Inoue et al., 1991; Janes and Knightley, 2004). Masaki and Uchida (2000) adopted a hydrothermal oxidation of titanium metal powder in concentrated potassium hydroxide solutions above $150^{\circ} \mathrm{C}$ to obtain potassium titanates $\left(\mathrm{K}_{2} \mathrm{Ti}_{2} \mathrm{O}_{5}, \mathrm{~K}_{4} \mathrm{Ti}_{3} \mathrm{O}_{8}\right.$ and $\left.\mathrm{KTiO}_{2}(\mathrm{OH})\right)$ as a single phase and fibrous amorphous product that was transformed into $\mathrm{K}_{2} \mathrm{Ti}_{4} \mathrm{O}_{9}, \mathrm{~K}_{2} \mathrm{Ti}_{6} \mathrm{O}_{13}$ or $\mathrm{K}_{2} \mathrm{Ti}_{2} \mathrm{O}_{5}$ by calcination. Hydrothermal reaction of $\mathrm{TiO}_{2}$ nanoparticles and $\mathrm{KOH}$ solution resulted in titanate $\left(\mathrm{K}_{2} \mathrm{Ti}_{6} \mathrm{O}_{13}\right)$ nanowires with diameters of $\sim 10 \mathrm{~nm}$ and length ranges from $500 \mathrm{~nm}$ to $2 \mu \mathrm{m}$ (Du et al., 2003a). Fine nanowires of $\mathrm{K}_{2} \mathrm{Ti}_{8} \mathrm{O}_{17}$ with diameters of 5-10 $\mathrm{nm}$ and a surface area > $300 \mathrm{~m}^{2} / \mathrm{g}$ have been synthesised by a hydrothermal treatment of titania particles with $\mathrm{KOH}$ solution (Yuan et al., 2004). Due to their large surface areas, titanate nanowires have potential applications in environmental purification with enhanced photocatalytic activity ( $\mathrm{Du}$ et al., 2003b; Fujishima and Honda, 1972). 
In the past decades, there have been several reports on the synthesis and characterisation of potassium titanate nanostructures by high temperature hydrothermal treatment of powdered $\mathrm{TiO}_{2}$ in a strong aqueous alkaline solution. Potentially, nanostructured titanates can be utilised in applications including catalysis, photocatalysis, lithium batteries and solar cells. However, rapid preparation route combining the use of low temperature, atmospheric pressure and simple apparatus in the preparation of higher-order assemblies of titanate has not been well investigated. Therefore, in this work, attempts have been made to achieve a faster rate of nanofibre formation by carrying out reflux synthesis in a mixture of aqueous $\mathrm{KOH}$ and $\mathrm{H}_{2} \mathrm{O}_{2}$ at relatively low temperature. We report here on the synthesis of potassium titanate nanostructures utilising a redox strategy combined with a hydrothermal reaction involving $\mathrm{TiO}_{2}$ powder, a basic $\mathrm{KOH}$ solution and an oxidising $\mathrm{H}_{2} \mathrm{O}_{2}$ solution. The adoption of the environmentally friendly $\mathrm{H}_{2} \mathrm{O}_{2}$-assisted hydrothermal route has been employed to synthesise other inorganic materials under hydrothermal conditions (Li et al., 2006; Piquemal et al., 2013). The nanostructures were characterised and tested for adsorption and photocatalytic activity using crystal violet (CV) as a model pollutant.

\section{Experimental}

\subsection{Materials}

Titanium dioxide (Degussa P25) was used for the synthesis of potassium titanate. P25 is a mixed phase nanopowder with $70 \%$ anatase and $30 \%$ rutile with a surface area of $50 \mathrm{~m}^{2} / \mathrm{g}$ and a mean primary particle size of about $30 \mathrm{~nm}$. Hydrogen peroxide $(50 \% \mathrm{w} / \mathrm{w})$ was obtained from Australian Scientific Pty Ltd., hydrochloric acid (37\%, v/v) from ScharlauChemie S.A., and potassium hydroxide $(85 \%, w / w)$ and crystal violet $(86 \%, w / w)$ from ChemSupply. Milli$\mathrm{Q}$ water was used to prepare solutions and to wash powder samples.

\subsection{Synthesis}

A modified peroxotitanate method was adopted, which involved mixing $2 \mathrm{~g}$ of P25 powder with $1 \%$ (designated as method A), 3\% (designated as method B) and 5\% (designated as method $\mathrm{C})$ of $\mathrm{H}_{2} \mathrm{O}_{2}(50 \% w / w)$ in $10 \mathrm{M}$ of $\mathrm{KOH}$. For example, to prepare the samples through method A, $2 \mathrm{~g} \mathrm{P} 25$ powder was added to a solution containing $1 \mathrm{~mL} \mathrm{H}_{2} \mathrm{O}_{2}$ and $99 \mathrm{~mL}$ $\mathrm{KOH}$. The mixtures were homogenised using a magnetic stirrer and placed separately into Teflon-coated containers, which were sealed and heated at $100^{\circ} \mathrm{C}$ in an oven for $24 \mathrm{hr}$. After the hydrothermal treatment, the autoclave was naturally cooled to room temperature. The 
solid specimens were recovered by centrifugation (Centurion Sci., 2040) at $3000 \mathrm{r} / \mathrm{min}$ for 5 min, washed with $1 \mathrm{M} \mathrm{HCl}$ solution and Milli-Q water until $\mathrm{pH} \mathrm{7,} \mathrm{and} \mathrm{then} \mathrm{dried} \mathrm{in} \mathrm{oven} \mathrm{at}$ $100^{\circ} \mathrm{C}$ for $12 \mathrm{hr}$. The obtained powder samples, designated as $\mathrm{A}, \mathrm{B}$, and $\mathrm{C}$ from their respective synthesis methods, were also calcined in a furnace (Labec, CE-MLS) at $600^{\circ} \mathrm{C}$ for $4 \mathrm{hr}$ and these samples are designated as $\mathrm{AC}, \mathrm{BC}$ and $\mathrm{CC}$, respectively.

\subsection{Characterisation}

Morphology and elemental composition analyses were carried out using a scanning electron microscope (SEM, Hitachi S-4700) equipped with an energy dispersive X-ray detector (EDX250 supplied by Horiba) operating at $15 \mathrm{kV}$. A Philips CM200 (Netherlands) transmission electron microscope (TEM) operating at $200 \mathrm{kV}$ was employed to obtain micrographs of the specimens. X-ray diffraction (XRD) patterns were generated on a MDI Jade 5.0 (MaterialsData Inc., USA) X-ray diffractometer with $\mathrm{Cu} \mathrm{K} \alpha$ radiation source. The data were measured within the range of scattering angle $2 \theta$ of $5^{\circ}-90^{\circ}$. Powders of specimens were used without further treatment. Brunauer, Emmet and Teller (BET) surface area analyses were performed on an automated surface area analyser (Micromeritics Gemini 2360, USA) by means of nitrogen adsorption-desorption. The BET surface area was determined by a multipoint BET method using the adsorption data in the relative pressure $\left(P / P_{0}\right)$ range of $0.05-0.18$. The mean pore diameter and the total pore volume of samples were determined from the desorption isotherm via Barret-Joyner-Halender (BJH) model.

\subsection{Adsorption and photocatalysis}

$\mathrm{CV}$ powder was dissolved in pure water to prepare a stock solution of $10 \mathrm{mg} / \mathrm{L}$ concentration and the $\mathrm{pH}$ of the solution was adjusted to 7 using $0.1 \mathrm{~N} \mathrm{NaOH}$. Dye adsorption experiments were carried out in an orbital shaking incubator (TU-400, Thermoline Sci.) operating at 150 $\mathrm{r} / \mathrm{min}$ and $25^{\circ} \mathrm{C}$ for $30 \mathrm{~min}$ to reach adsorption equilibrium. Samples were collected and filtered through $0.45 \mu \mathrm{m}$ (PTTF) syringe filters before analyses.

The photocatalytic activity of potassium titanates was assessed by batch experiments using a $2 \mathrm{~L}$ volume of stock $\mathrm{CV}$ solution. After the addition of $0.05 \mathrm{~g} / \mathrm{L}$ photocatalyst, the slurry was mixed with a magnetic stirrer at $400 \mathrm{r} / \mathrm{min}$ for $30 \mathrm{~min}$ for dark adsorption. The cylindrical reactor $(40 \mathrm{~cm} \times 10 \mathrm{~cm})$ vessel had three $(15 \mathrm{~W}$ each) immersed UVC lamps (Perkin Elmer), a temperature controlling device and an air sparger $(0.6 \mathrm{~L} / \mathrm{min})$ to provide dissolved oxygen. Photocatalysis was carried out for $120 \mathrm{~min}$ at a stable temperature of $26^{\circ} \mathrm{C}$. Slurry samples 
were collected at $15 \mathrm{~min}$ intervals and analysed for $\mathrm{CV}$ decomposition at $\lambda=590 \mathrm{~nm}$ using a Shimadzu UV-Vis1700 spectrophotometer.

\subsection{Separation by settling}

After the photocatalysis procedure, separation of catalyst particles was studied by monitoring the turbidity of the supernatant as a function of time at room temperature. Samples were collected at specific time intervals $(0,15,30,60,90$ and $120 \mathrm{~min})$ at a depth of $5 \mathrm{~cm}$ and examined for changes in turbidity. The turbidity was measured using a turbidity and chlorine meter (HI 93414, Hanna instruments, USA), which was calibrated using standard turbidity solutions.

\section{Results and discussion}

\subsection{Characterisation of potassium titanate}

Surface area, pore size and pore volume were determined using BET analysis. The data obtained from $\mathrm{N}_{2}$ adsorption-desorption isotherms revealed typical IUPAC type (III) adsorption characteristics, with a significant hysteresis loop. The data shown in Table 1 indicate that the obtained potassium titanates are macroporous (pore diameter $>50 \mathrm{~nm}$ ) materials. The surface area of P25 powder was $50 \mathrm{~m}^{2} / \mathrm{g}$ but after hydrothermal growth, the surface area of specimens A, B and C increased to 330.1, 263.7 and $235.8 \mathrm{~m}^{2} / \mathrm{g}$, respectively. The increase in surface area of A, B and C can be attributed to the morphology change from nanoparticles to nanostructures (Di Wu et al., 2006; El Saliby et al., 2011; Sikhwivhilu et al., 2012; Yuan and $\mathrm{Su}, 2004)$. However, after calcination at $600^{\circ} \mathrm{C}$, the BET surface area of specimens AC, BC and CC decreased significantly to $116.3,105.1$ and $84.9 \mathrm{~m}^{2} / \mathrm{g}$, which is attributed to a change from nanotubes to nanorods at this temperature (Xiao et al., 2010; Yuan and Su, 2004). The total pore volume of potassium titanate showed an expected decrease, whereas the mean pore diameter increased after calcination. The total pore volume decrease is due to the collapse of small pores during the calcination process (El Saliby et al., 2011; Zhou et al., 2009).

SEM images of the potassium titanate specimen revealed longitudinally-oriented wire-like structures with a length up to several micrometres and diameters ranging from 10 to $30 \mathrm{~nm}$ (Fig. 1). This hierarchical 3D nanowire network structure growth was formed by joining or welding P25 nanoparticles in $\mathrm{KOH}$ solution (Hu et al., 2013). Under hydrothermal condition, titania reacted with $\mathrm{KOH}$ solution and potassium titanate nanocrystallines were 
created. These nanocrystallines began to grow on the substrate through dissolutionrecrystallisation process forming nanowire-like structure (Hu et al., 2011).

TEM images showed belt-like structures of an isolated fibre, which was clearly visible in the transmitted electron image (Fig. 2). The presence of lattice fringes indicated that the potassium titanate nanowires have a crystalline structure aligned with orientation of their basal nanobelts. Parallel fringes in the walls correspond to a distance of about $1 \mathrm{~nm}$, which can also be detected as abroad reflection by X-ray and electron diffraction (Patzke et al., 2002).

The XRD peaks of P25 and potassium titanate powders were recorded for $2 \theta$ diffraction angles from $5^{\circ}$ to $90^{\circ}$ (Fig. 3). The precursor (Evonik P25) is a mixed phase catalyst showing anatase and rutile peaks. Five primary peaks of anatase phase at $25.42^{\circ}$, $37.12^{\circ}, 48.05^{\circ}, 54.37^{\circ}$ and $63.19^{\circ}$ were recorded, while small diffraction peaks at $27.5^{\circ}$ and $55.4^{\mathrm{O}}$ indicated the rutile phase. The XRD spectra of samples A, B and C were attributed to the transfer of a portion of anatase into mixed species of potassium titanate, and were recovered by calcining the specimens (i.e., $\mathrm{AC}, \mathrm{BC}$ and $\mathrm{CC}$ ) at $600^{\circ} \mathrm{C}$ for $4 \mathrm{hr}$. Calcination at high temperature resulted in the stronger diffraction peak, which indicates the formation of titania anatase (Xiao et al., 2010). Mixed species $\left(\mathrm{K}_{2} \mathrm{Ti}_{8} \mathrm{O}_{17}, \mathrm{~K}_{2} \mathrm{Ti}_{6} \mathrm{O}_{13}, \mathrm{~K}_{2} \mathrm{TiO}_{3}\right.$ and $\left.\mathrm{K}_{3} \mathrm{Ti}_{8} \mathrm{O}_{17}\right)$

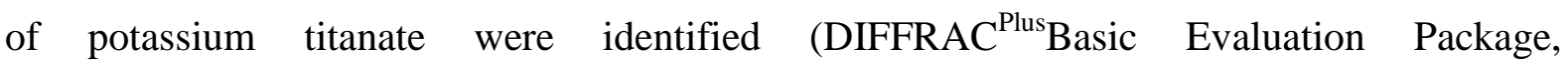
SEARCH/MATCH 10.1, Release 2004) as possible crystallisation sites under hydrothermal treatment in aqueous solution of $\mathrm{H}_{2} \mathrm{O}_{2}$ and $\mathrm{KOH}$. This was consistent with TEM images (Fig. 2), which revealed that some fraction of anatase was transformed into potassium titanate nanowires after $24 \mathrm{hr}$ (Riss et al., 2007). EDX analysis conformed empirical composition of $45.97 \mathrm{wt} \% \mathrm{Ti}$ which was observed to be in accordance with the theoretical compositions with the standard deviation of $\pm 3 \%$ (Table 2).

\subsection{Adsorption of crystal violet on potassium titanate}

The adsorption of CV on the surface of the catalysts was studied and the results are shown in Fig. 4). Dispersed powders were coloured purplish-blue after mixing them with CV stock solution, indicating that the removal of $\mathrm{CV}$ is due to the adsorption of $\mathrm{CV}$ molecules on the potassium nanowires. After $30 \mathrm{~min}$, the complete decolourisation was reached for $\mathrm{A}$ and $\mathrm{B}$, which completely adsorbed $\mathrm{CV}$ at $0.05 \mathrm{~g} / \mathrm{L}$ catalyst loading. Catalyst $\mathrm{A}$ showed superior colour adsorption capacity. Adsorption followed the trend $\mathrm{A}>\mathrm{B}>\mathrm{C}>\mathrm{AC}>\mathrm{BC}>\mathrm{CC}$. Catalyst A had the greatest surface area $\left(330.1 \mathrm{~m}^{2} / \mathrm{g}\right)$ and largest pore volume $\left(1.27 \mathrm{~cm}^{3} / \mathrm{g}\right)$. 
Calcination had little negative effect on the adsorption capacity of the fibrous nanowires at low powder loading $(0.05,0.1$ and $0.2 \mathrm{~g} / \mathrm{L})$ but no effect on high loading $(0.5 \mathrm{~g} / \mathrm{L})$. This can be explained by the decrease in surface area, pore volume and the increase of mean pore diameter. The effect of surface area of the catalysts on CV adsorption revealed that asprepared potassium nanowire-assemblies are more effective adsorbent of $\mathrm{CV}$ than calcined nanowires. It was because the biggest surface area showed the highest CV adsorption, while calcined specimens showed the lowest overall adsorption.

\subsection{Photocatalytic decolouration of crystal violet}

The photocatalytic activity of synthesised potassium titanate was assessed by batch experiments using a $2 \mathrm{~L}$ volume of $10 \mathrm{mg} / \mathrm{L} \mathrm{CV}$ solution with $0.05 \mathrm{~g} / \mathrm{L}$ catalyst loading. Degussa P25 was used as a reference photocatalyst. CV was adsorbed onto the catalysts surface for $30 \mathrm{~min}$ in the dark before UV lamps were switched on. The decolourisation of the slurry was complete after $2 \mathrm{hr}$ of illumination and $\mathrm{CV}$ removal was assessed by the decrease in the absorbance at $590 \mathrm{~nm}$.

Figure 5 shows the photocatalytic degradation of CV under UV light over time. Heterogeneous photocatalysis over titania follows a well-defined mechanism, which is initiated by the adsorption of efficient photons by titania, and is maintained through a series of reactions that involve the production of positives holes $\left(\mathrm{h}^{+}\right)$and hydroxyl radicals $\left(\mathrm{OH}^{*}\right)$ (Senthilkumaar and Porkodi, 2005). The photooxidation of organic compounds is thus reached via successive attacks by $\mathrm{OH}^{*}$. In the present study, the photooxidation of the slurry was completed after 150 min illumination, and was around $90 \%$ for $\mathrm{A}$, and $85 \%$ for $\mathrm{B}$ followed by $\mathrm{AC}>\mathrm{C}>\mathrm{BC}>\mathrm{CC}$. The results showed that catalyst A was comparatively the best photocatalyst in terms of $\mathrm{CV}$ decolourisation. After $30 \mathrm{~min}$ of UV illumination, the removal of $\mathrm{CV}$ using macroporous nanowires decreased in the order $\mathrm{A}>\mathrm{B}>\mathrm{C}>\mathrm{AC}>\mathrm{P} 25$ $>\mathrm{BC}>\mathrm{CC}$. The calcination of powders had negative effect on the increase of the photoactivity of the catalysts, which can be described via the changes in morphology. Macroporous nanowires had lower BET surface area and pore volume after calcination, which decreased their photocatalytic activity.

\subsection{Supernatant turbidity}

For photocatalytic water treatment processes, separation of catalysts is a real burden after photocatalysis. Hence, prepared photocatalysts were investigated for their ability to separate. Turbidity meter was used to monitor the decrease in solution turbidity over time which 
indicates an increase in the sedimentation rate of suspended particles. In Fig. 6, normalised turbidity were plotted to compare separation ability of all photocatalysts. After $2 \mathrm{~h}$ of static conditions, the decrease in solution turbidity was recorded as $75 \%$ for $\mathrm{CC}$ and $60 \%$ for $\mathrm{C}$, while it was approximately $40 \%$ for $\mathrm{A}, \mathrm{AC}, \mathrm{B}$ and $\mathrm{BC}$. On the other hand, the turbidity of P25 suspension was obtained relatively high with only a $30 \%$ decrease in turbidity after $2 \mathrm{hr}$ at static conditions.

\section{Conclusions}

Potassium titanate nanostructures were synthesised using a hydrothermal method. Longitudinally-oriented wire-like structures with a length up to several micrometers and diameters ranging from 10 to 20 nanometres were produced by the treatment of $\mathrm{TiO}_{2}(\mathrm{P} 25)$ with $\mathrm{KOH}$ and $\mathrm{H}_{2} \mathrm{O}_{2}$. Potassium titanate 'A' showed superior photocatalyst activity following the trend $\mathrm{A}>\mathrm{B}>\mathrm{C}>\mathrm{AC}>\mathrm{BC}>\mathrm{CC}$. Larger pore size fibrous nanowires resulting from this treatment showed high affinity in adsorbing $\mathrm{CV}$, which was mainly due to the high surface area. The binding of $\mathrm{K}^{+}$and peroxo groups had detrimental effect on the adsorption of the cationic dye because of surface saturation, which decreased the adsorption sites. The decolourisation revealed their photocatalytic activity under UV light irradiation. The macroporous nanowires are considered as effective adsorbents of $\mathrm{CV}$ and are also capable of photocatalytic degradation. Furthermore, they can be easily separated from the solution by settling.

\section{Acknowledgments}

This research was funded by an Australian Research Council-Linkage Project (LP0991544), and a UTS and Australian Postgraduate Award scholarship.

\section{References:}

Bavykin, D.V., Friedrich, J.M., Walsh, F.C., 2006. Protonated titanates and $\mathrm{TiO}_{2}$ nanostructured materials: synthesis, properties, and applications. Adv. Mater. 18(21), 2807-2824.

Berry, K., Aftandilian, V., Gilbert, W., Meibohm, E., Young, H., 1960. Potassium tetra-and hexatitanates. J. Inor. Nucl. Chem. 14(3), 231-239. 
Chen, Q., Peng, L.M., 2007. Structure and applications of titanate and related nanostructures. Inter. J. Nanotechnol. 4(1), 44-65.

Chen, X.B., Mao, S.S., 2007. Titanium dioxide nanomaterials: synthesis, properties, modifications, and applications. Chem. Rev. 107(7), 2891-2959.

Wu, D., Liu, J., Zhao, X., Li, A., Chen, Y., Ming, N., 2006. Sequence of events for the formation of titanate nanotubes, nanofibers, nanowires, and nanobelts. Chem. Mater. 18(2), 547-553.

Dmitry, V.B., Barbara, A.C., Mark, E.L., Frank, C.W., 2008. An aqueous, alkaline route to titanate nanotubes under atmospheric pressure conditions. Nanotechnology 19(27), 275604.

Du, G., Chen, Q., Han, P., Yu, Y., Peng, L.M., 2003a. Potassium titanate nanowires: Structure, growth, and optical properties. Phys. Rev. B. 67(3), 035323.

Du, G.H., Chen, Q., Han, P.D., Yu, Y., Peng, L.M., 2003b. Potassium titanate nanowires: Structure, growth, and optical properties. Phys. Rev. B. 67(3), 035323.

El Saliby, I., Erdei, L., Shon, H.K., Kim, J.B., Kim, J.H., 2011. Preparation and characterisation of mesoporous photoactive Na-titanate microspheres. Catal. Today 164(1), 370-376.

Fujishima, A., Honda, K., 1972. Electrochemical photolysis of water at a semiconductor electrode. Nature 238(5358), 37-38.

Hu, A., Liang, R., Zhang, X., Kurdi, S., Luong, D., Huang, H. et al., 2013. Enhanced photocatalytic degradation of dyes by $\mathrm{TiO}_{2}$ nanobelts with hierarchical structures. J. Photochem. Photobiol. A: Chem. 256, 7-15.

Hu, K.S., Xiao, X., Cao, X.F., Hao, R., Zuo, X.L., Zhang, X.J. et al., 2011. Adsorptive separation and photocatalytic degradation of methylene blue dye on titanate nanotube powders prepared by hydrothermal process using metal Ti particles as a precursor. J. Hazard. Mater. 192(2), 514-520.

Inoue, Y., Kubokawa, T., Sato, K., 1991. Photocatalytic activity of alkali-metal titanates combined with ruthenium in the decomposition of water. J. Phys. Chem. 95(10), 4059-4063.

Ishihara, Y., Kyono, H., Kohyama, N., Otaki, N., Serita, F., Toya, T., 2002. Effects of surface characteristics of potassium titanate whisker samples on acute lung injury induced by a single intratracheal administration in rats. Inhala. Toxicol. 14(5), 503-519. 
Izawa, H., Kikkawa, S., Koizumi, M., 1982. Ion exchange and dehydration of layered [sodium and potassium] titanates, $\mathrm{Na}_{2} \mathrm{Ti}_{3} \mathrm{O}_{7}$ and $\mathrm{K}_{2} \mathrm{Ti}_{4} \mathrm{O}_{9}$. J. Phys. Chem. J. Phys. Chem. 86(25), 5023-5026.

Janes, R., Knightley, L., 2004. Crystallization and phase evolution of potassium titanates from alkoxide derived precipitates. J. Mater. Sci. 39(7), 2589-2592.

Lee, C.T., Um, M.H., Kumazawa, H., 2000. Synthesis of titanate derivatives using ionexchange reaction. J. Amer. Ceram. Soc. 83(5), 1098-1102.

Li, G.C., Pang, S.P., Jiang, L., Guo, Z.Y., Zhang, Z.K., 2006. Environmentally friendly chemical route to vanadium oxide single-crystalline nanobelts as a cathode material for lithium-ion batteries. J. Phys. Chem. B. 110(19), 9383-9386.

Masaki, N., Uchida, S., Yamane, H., Sato, T., 2000. Hydrothermal synthesis of potassium titanates in Ti-KOH-H${ }_{2} \mathrm{O}$ system. J. Mater. Sci. 35(13), 3307-3311.

Morgan, D.L., Zhu, H.Y., Frost, R.L., Waclawik, E.R., 2008. Determination of a morphological phase diagram of Titania/Titanate nanostructures from alkaline hydrothermal treatment of degussa P25. Chem. Mater. 20(12), 3800-3802.

Patzke, G.R., Krumeich, F., Nesper, R., 2002. Oxidic nanotubes and nanorods-anisotropic modules for a future nanotechnology. Ang. Chem. Inter. Ed. 41(14), 2446-2461.

Piquemal, J.Y., Briot, E., Brégeault, J.M., 2013. Preparation of materials in the presence of hydrogen peroxide: from discrete or "zero-dimensional" objects to bulk materials. Dalton Transac. 42(1), 29-45.

Riss, A., Berger, T., Grothe, H., Bernardi, J., Diwald, O., Knözinger, E., 2007. Chemical control of photoexcited states in titanate nanostructures. Nano. Lett. 7(2), 433-438.

Senthilkumaar, S., Porkodi, K., 2005. Heterogeneous photocatalytic decomposition of Crystal Violet in UV-illuminated sol-gel derived nanocrystalline $\mathrm{TiO}_{2}$ suspensions. J. Coll. Inter. Sci. 288(1), 184-189.

Sikhwivhilu, L.M., Mpelane, S., Mwakikunga, B.W., Sinha Ray, S., 2012. Photoluminescence and hydrogen gas-sensing properties of titanium dioxide nanostructures synthesized by hydrothermal treatments. ACS Appl. Mater. Inter. 4(3), 1656-1665. 
Um, M.H., Lee, C.T., Kumazawa, H., 2001. Thermal treatment of titanate derivatives synthesized by ion- exchange reaction. J. Amer. Ceram. Soc. 84(5), 1181-1183.

Xiao, Y.M., Wu, J.H., Yue, G.T., Xie, G.X., Lin, J.M., Huang, M.L., 2010. The preparation of titania nanotubes and its application in flexible dye-sensitized solar cells. Electroc. Acta 55(15), 4573-4578.

Yang, J.J., Jin, Z.S., Wang, X.D., Li, W., Zhang, J.W., Zhang, S.L. et al., 2003. Study on composition, structure and formation process of nanotube $\mathrm{Na}_{2} \mathrm{Ti}_{2} \mathrm{O}_{4}(\mathrm{OH})_{2}$. Dalton Transac. (20), 3898-3901.

Yuan, Z.Y., Su, B.L., 2004. Titanium oxide nanotubes, nanofibers and nanowires. Coll. Surf. A. 241(1), 173-183.

Yuan, Z.Y., Zhang, X.B., Su, B.L., 2004. Moderate hydrothermal synthesis of potassium titanate nanowires. Appl. Phys. A. 78(7), 1063-1066.

Zhou, M., Yu, J., Liu, S., Zhai, P., Huang, B., 2009. Spray-hydrolytic synthesis of highly photoactive mesoporous anatase nanospheres for the photocatalytic degradation of toluene in air. Appl. Catal. B. 89(1), 160-166.

Zhuang, G.S., Sui, G.X., Meng, H., Sun, Z.S., Yang, R., 2007. Mechanical properties of potassium titanate whiskers reinforced poly (ether ether ketone) composites using different compounding processes. Compos. Sci. Technol.Compos. Sci. Technol. 67(6), $1172-1181$. 
Table 1 Textural parameter of nanomaterial synthesis in this study

\begin{tabular}{cccc}
\hline Sample & $\begin{array}{r}\text { BET surface area } \\
\left(\mathrm{m}^{2} / \mathrm{g}\right)\end{array}$ & $\begin{array}{r}\text { Total pore volume } \\
\left(\mathrm{cm}^{3} / \mathrm{g}\right)\end{array}$ & $\begin{array}{c}\text { Mean pore diameter } \\
(\AA)\end{array}$ \\
\hline P25 & 57.14 & 0.4277 & 80.72 \\
A & 330.10 & 1.271 & 96.11 \\
AC & 116.30 & 0.6063 & 150.70 \\
B & 263.68 & 1.1644 & 95.16 \\
BC & 105.09 & 1.482 & 129.52 \\
C & 235.81 & 1.103 & 104.26 \\
CC & 84.92 & 0.8928 & 208.96 \\
\hline
\end{tabular}

Table 2 Elemental composition of the as-prepared (A, B and C) and calcined samples (AC, $\mathrm{BC}$ and $\mathrm{CC})$.

\begin{tabular}{lllllllll} 
& Elements & $\mathrm{P} 25$ & $\mathrm{~A}$ & $\mathrm{AC}$ & $\mathrm{B}$ & $\mathrm{BC}$ & $\mathrm{C}$ & $\mathrm{CC}$ \\
\cline { 2 - 8 } Weight\% & $\mathrm{O}$ & 52.37 & 41.65 & 43.20 & 45.82 & 41.06 & 43.51 & 44.11 \\
& $\mathrm{~K}$ & - & 10.85 & 9.48 & 11.69 & 11.15 & 10.63 & 11.00 \\
& $\mathrm{Ti}$ & 47.63 & 47.50 & 47.32 & 42.49 & 47.79 & 45.86 & 44.89 \\
\cline { 2 - 8 } Atomic\% & $\mathrm{O}$ & 69.27 & 58.59 & 64.20 & 62.50 & 61.43 & 62.32 & 64.96 \\
& $\mathrm{~K}$ & - & 12.31 & 9.04 & 12.22 & 10.35 & 10.96 & 9.78 \\
& $\mathrm{Ti}$ & 30.73 & 29.09 & 26.76 & 25.28 & 28.22 & 26.71 & 25.26 \\
\hline
\end{tabular}



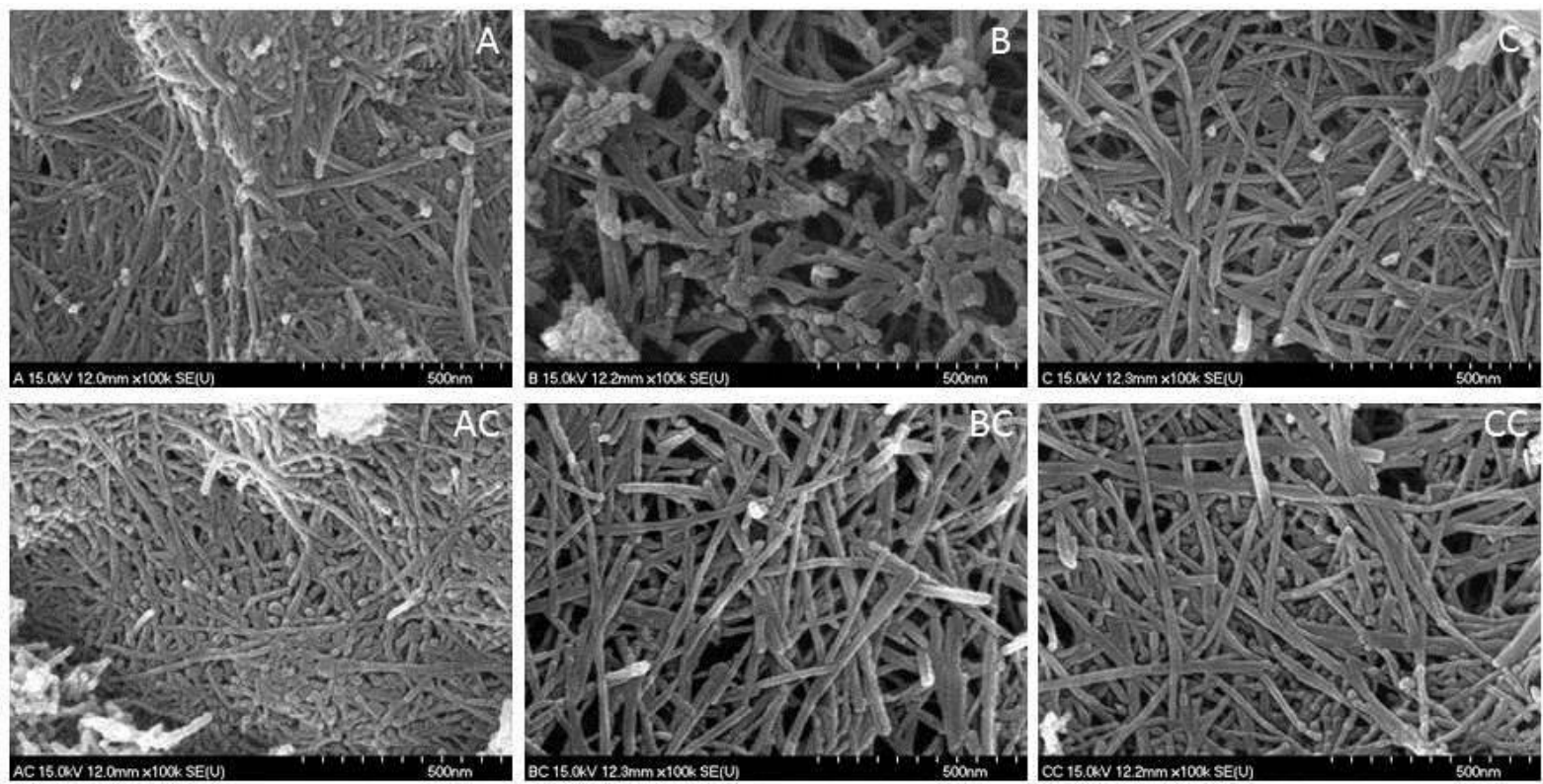

Fig. 1 SEM images of the potassium titanate powders: as-prepared (A, B, and C) and calcined samples (AC, BC and CC). 

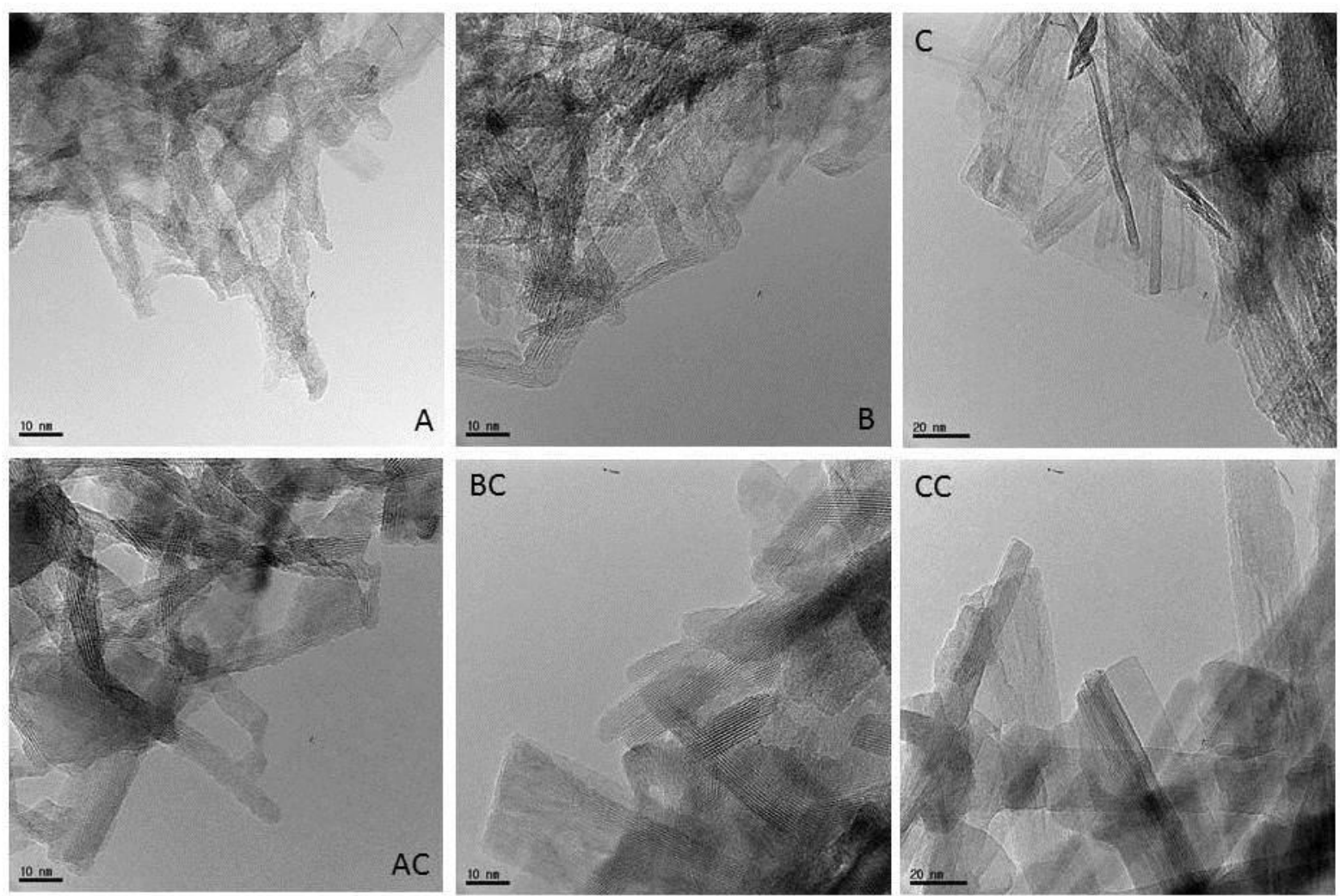

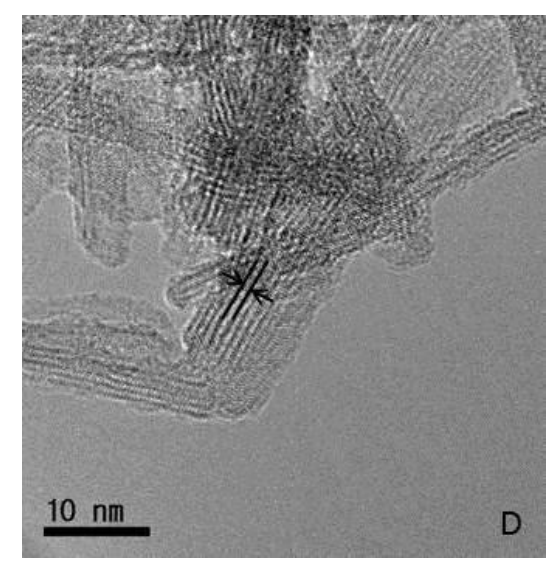

Fig. 2 TEM images of potassium titanate powders: as-prepared (A, B, and C), and calcined samples (AC, BC and CC). The presence of crystalline lattice fringes oriented parallel to the belt orientation with a distance of about $1 \mathrm{~nm}(\mathrm{D})$. 


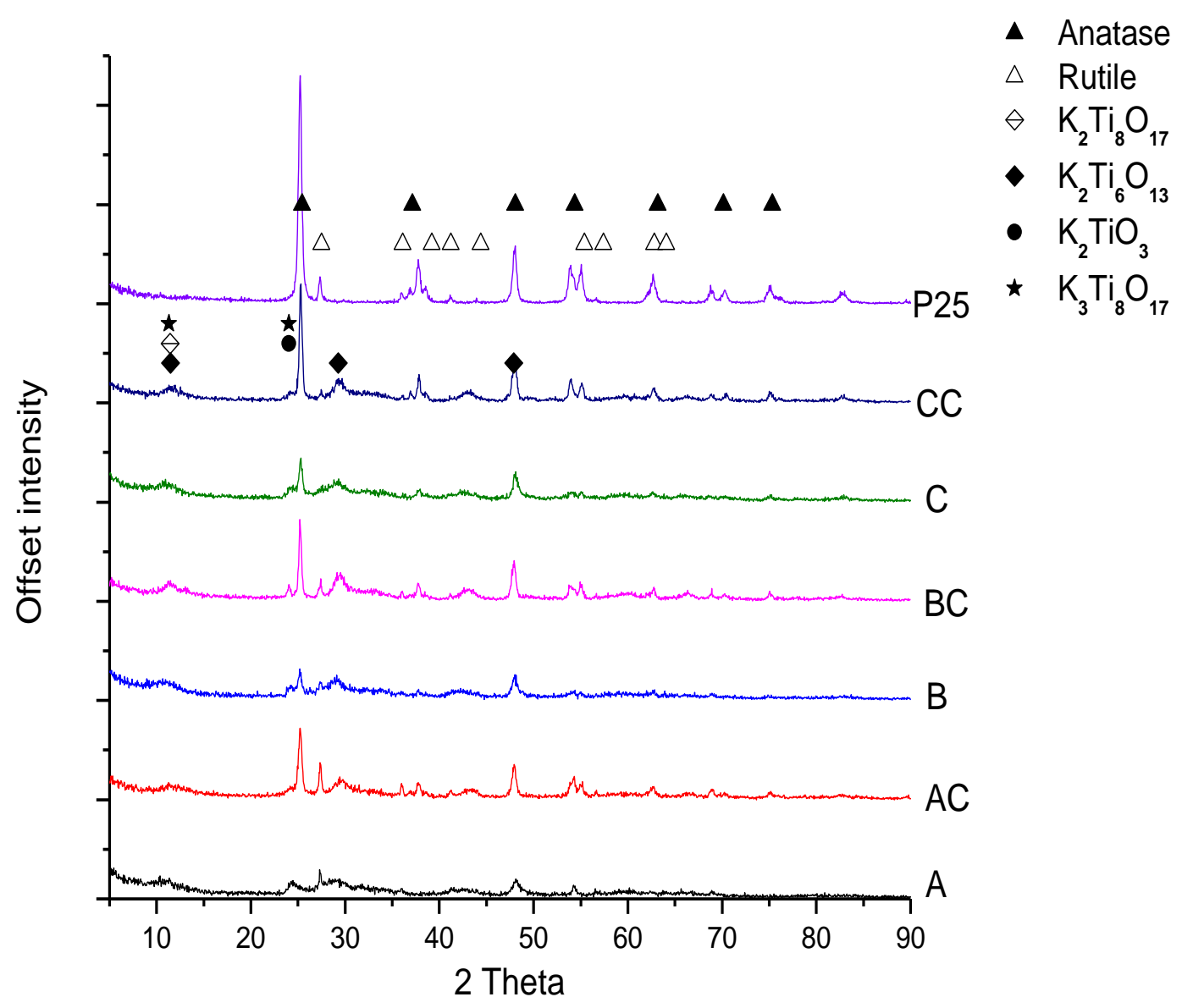

Fig. 3 Powder XRD patterns of Degussa P25 and of the as-prepared (A, B and C) and calcined samples (AC, BC and $\mathrm{CC})$. 


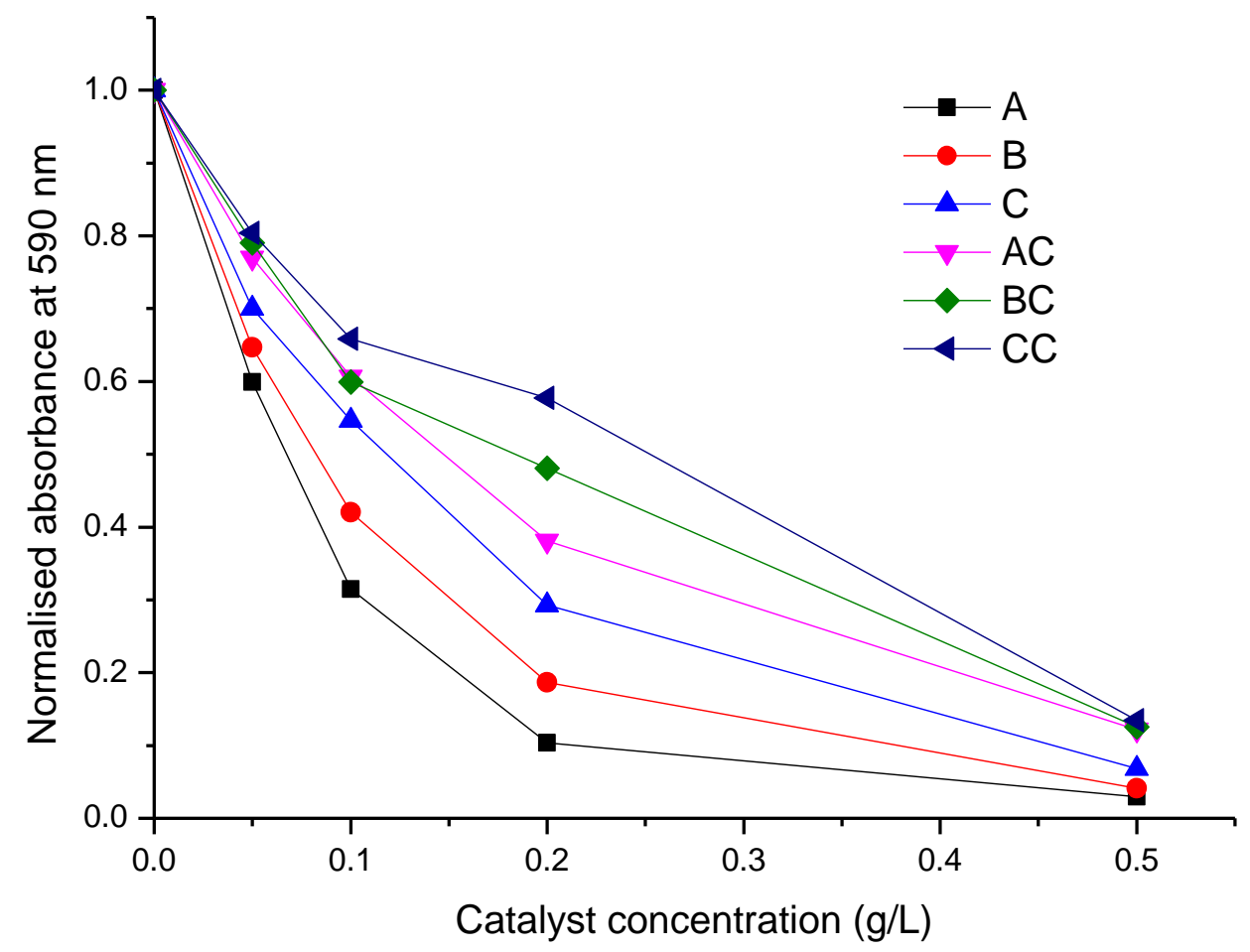

Fig. 4 Decolouration of $10 \mathrm{mg} / \mathrm{L} \mathrm{CV}$ solution by adsorption on as-prepared samples (A, B and $\mathrm{C}$ ) and calcined samples (AC, BC and $\mathrm{CC}$ ). 


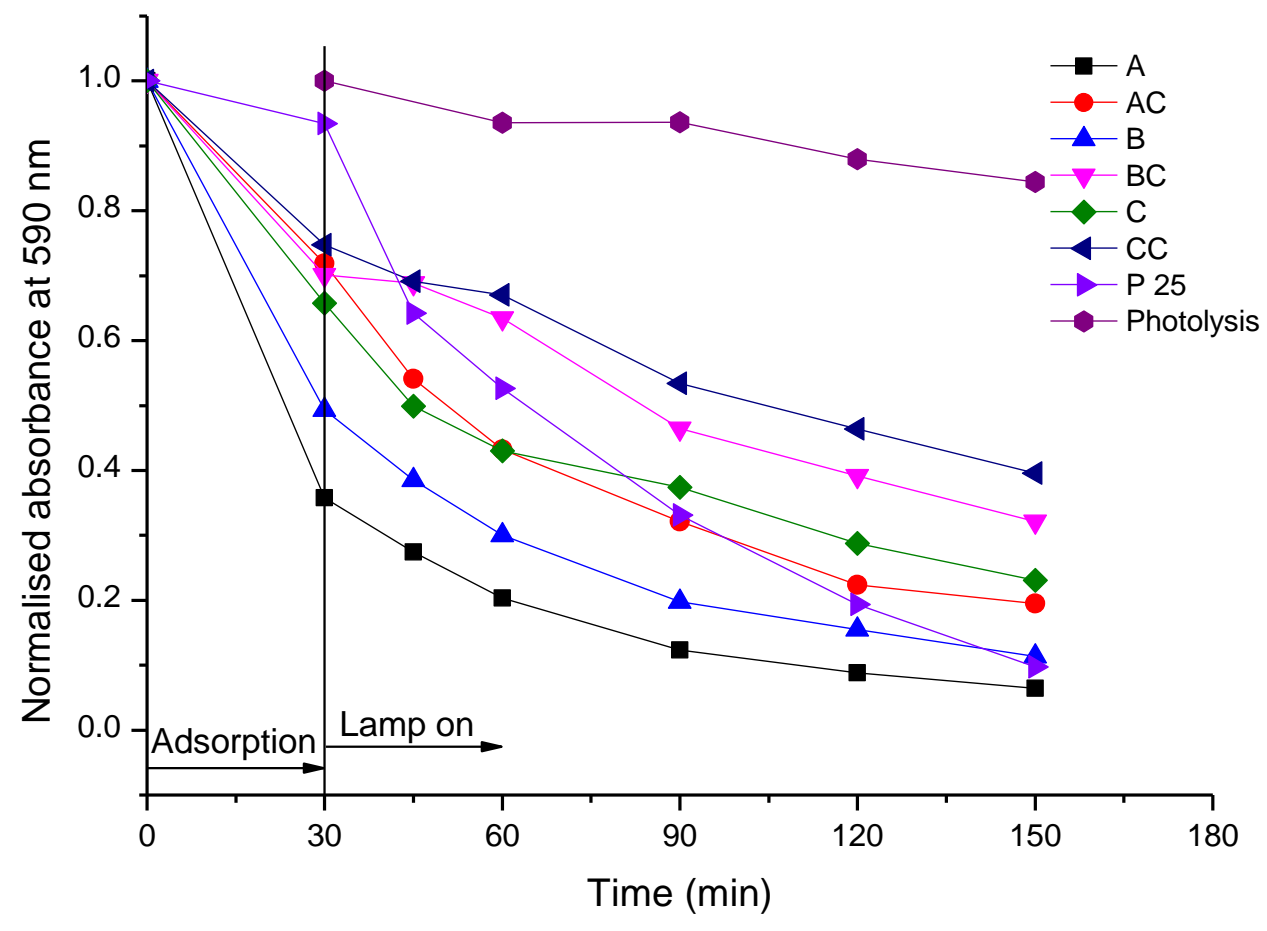

Fig. 5 Photodegradation of CV on Degussa P25, as-prepared potassium titanate (A, B and C) and respective calcined samples $(\mathrm{AC}, \mathrm{BC}$ and $\mathrm{CC})$. ([CV] $=10 \mathrm{mg} / \mathrm{L}, \mathrm{pH} 7$, photocatalyst loading $=0.05 \mathrm{~g} / \mathrm{L}$ ). 


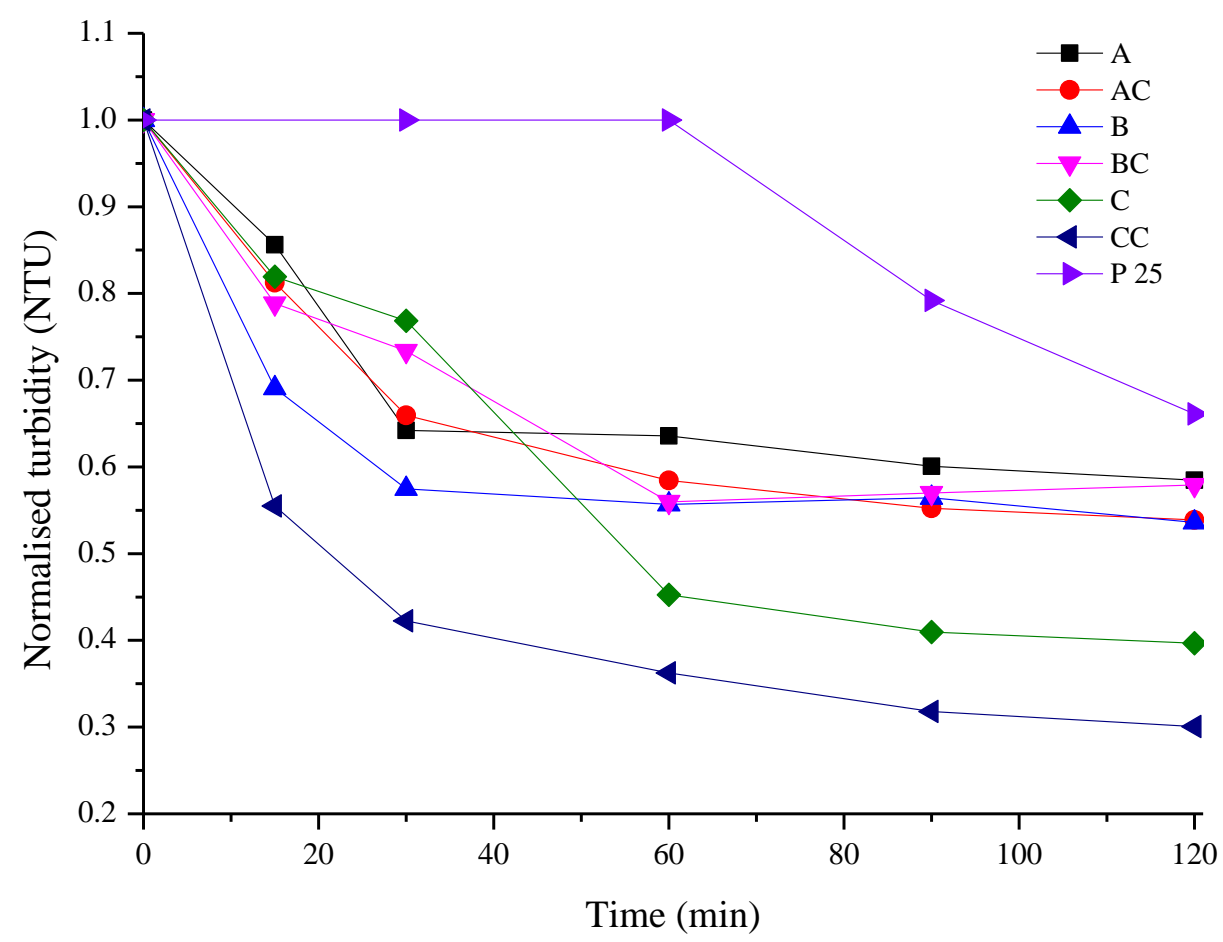

Fig. 6 Normalised decrease in the supernatant turbidity using prepared samples (A, B and C) and calcined samples (AC, BC and $\mathrm{CC}$ ) with $0.05 \mathrm{mg} / \mathrm{L}$ photocatalyst loading. 